\title{
QUEEN'S
UNIVERSITY
BELFAST
}

\section{Alcohol, smoking and the GI Tract}

McCain, S., \& Coleman, H. (2017). Alcohol, smoking and the GI Tract. Best Practice \& Research: Clinical Gastroenterology, 31(5), 489. https://doi.org/10.1016/j.bpg.2017.10.003

\section{Published in:}

Best Practice \& Research: Clinical Gastroenterology

\section{Document Version:}

Peer reviewed version

\section{Queen's University Belfast - Research Portal:}

Link to publication record in Queen's University Belfast Research Portal

\section{Publisher rights}

Copyright 2017 Elsevier.

This manuscript is distributed under a Creative Commons Attribution-NonCommercial-NoDerivs License

(https://creativecommons.org/licenses/by-nc-nd/4.0/), which permits distribution and reproduction for non-commercial purposes, provided the author and source are cited.

\section{General rights}

Copyright for the publications made accessible via the Queen's University Belfast Research Portal is retained by the author(s) and / or other copyright owners and it is a condition of accessing these publications that users recognise and abide by the legal requirements associated with these rights.

\section{Take down policy}

The Research Portal is Queen's institutional repository that provides access to Queen's research output. Every effort has been made to ensure that content in the Research Portal does not infringe any person's rights, or applicable UK laws. If you discover content in the Research Portal that you believe breaches copyright or violates any law, please contact openaccess@qub.ac.uk. 
Tobacco smoking and excessive alcohol consumption are known to have detrimental effects on multiple body organs including the cardiorespiratory system and gastrointestinal (GI) tract. The World Health Organisation estimate that 1.1 billion people smoke worldwide, and although this number is declining overall, prevalence continues to rise in certain regions, particularly in low and middle-income settings. Global prevalence of heavy episodic consumption of alcohol is also a major public health issue. An estimated $7.5 \%$ of adults are heavy drinkers, but this is considerably higher (up to 17\%) in some developed regions, such as Europe and North America. Public knowledge, and awareness amongst clinicians, of smoking and irresponsible alcohol consumption as 'bad' behaviours is generally well understood. However, there are some nuances, and research gaps, in the relationships between alcohol, smoking and the GI tract, that are described in detail in this issue.

Both tobacco smoke and alcohol are established carcinogens. Over 14 million new cancer diagnoses are made globally each year and four of the ten most common cancers develop within the GI tract. These include colorectal, gastric, liver and oesophageal cancer. The development of GI malignancies are multi-factorial, attributable to a combination of environmental and genetic factors. Overall, GI cancer incidence is increasing, but this has been met with advances in earlier detection of cancers, the development of new surgical techniques and improved chemotherapy agents to improve overall patient survival. However, further progress is required - for example, the success seen in improving colorectal cancer outcomes (in which the five-year survival is approximately 65\%) has not been replicated in oesophageal or pancreatic cancer, which have poor five-year survival rates of less than $20 \%$. Even though smoking and alcohol have been identified in epidemiological studies as modifiable risk factors involved in the aetiology of many (but not all) GI malignancies, understanding the role of these in an individual patient's disease course and prognosis is 
often unclear. Indeed, smoking and alcohol consumption can be an uncomfortable subject that may not be broached by many clinicians in discussions with these patients, for various (often appropriate) reasons. Although some progress has been made, there remains a need to better translate our knowledge of lifestyle factors including alcohol and smoking in GI cancer risk and prognosis, to educate the public and patients on these roles, and ultimately reduce cancer burden. If it were a medication that had beneficial effects (akin to smoking cessation or alcohol intake reduction), would we think twice about prescribing it?

The opportunity of a 'teachable moment' is a valuable one, and perhaps it is considered more feasible to discuss and address smoking and alcohol behaviours with individuals with premalignant, functional or benign GI diseases than cancer patients. Benign conditions of the GI tract, such as pancreatitis and inflammatory bowel disease (IBD), account for significant morbidity and mortality within the GI patient population. Furthermore, whilst the general trend of GI malignancy is to increase in incidence as individuals get older, benign conditions have a greater affinity for younger patients. This can mean a longer duration of disease and a significant impact on overall patient quality of life in patients with non-malignant, compared with malignant, GI conditions. IBD is one such example of a benign condition that can impact significantly on patient's quality of life. This can be through multiple hospital admissions for disease flare-up, surgical intervention for failed medical treatment and progression to malignant disease. As outlined in this issue, discussing smoking already plays a major role in IBD patient management.

This issue of Best Practice and Research: Clinical Gastroenterology is dedicated to up-todate reviews on the impact of smoking and alcohol on both malignant and benign conditions of the GI tract. The most common conditions are discussed in each chapter and summaries of 
evidence provided on the role of smoking and alcohol intake as a risk factors for these conditions, impacts of disease course and progression, symptom exacerbation, or patient management is provided. Underlying biological mechanisms and novel insights into alcohol, smoking and the gut microbiome are also provided. To complete this issue, there is a chapter dedicated to practical methods of communicating smoking and alcohol advice to patients. At the end of each chapter, key findings are highlighted along with gaps in the current research, and what could be done to address these.

We hope that this issue will improve the practice of evidence-based medicine with regards to lifestyle advice on alcohol and smoking for GI patients, alert researchers to gaps in our understanding, and consequently contribute towards improved quality of care offered to patients.

Stephen McCain, MB, Surgical Registrar, and Helen G. Coleman, PhD, Senior Lecturer Centre for Public Health, Queen's University Belfast, Belfast, Northern Ireland, BT12 6BJ Tel: 0044-(0)-2890978953 Email addresses: smcain02@qub.ac.uk; $\underline{\text { h.coleman@qub.ac.uk }}$ 